\title{
Hess and Pretori revisited: Resolution of some old contradictions
}

\author{
ALAN JACOBSEN \\ Boeing Commercial Airplane Company, Seattle, Washington \\ and \\ ALAN GILCHRIST \\ Institute for Cognitive Studies, Rutgers University, Newark, New Jersey
}

\begin{abstract}
An early experiment by Hess and Pretori (1894) was replicated and modified in an attempt to determine why they failed to find the ratio principle later discovered by Wallach (1948). Separating the two surround-infield patterns by darkness made very little difference. However, allowing the observer to adjust the infield luminance (as in Wallach) rather than the surround luminance (as in Hess \& Pretori) revealed some startling effects. At surround:infield luminance ratios greater than approximately 100:1, there is no ratio effect; all infields appear equal and totally dark. Converging evidence is presented that Hess and Pretori's data in this region actually represent surround-matching by the observers. Nor are ratio effects found with increments (infield brighter than surround). When free to match either infield luminances or ratios (by controlling infield luminance), observers match luminances. For decrements with ratios between 1:1 and approximately 100:1, lightness constancy and the ratio principle hold.
\end{abstract}

One of the most extensive experiments in simultaneous contrast was published by Hering's students Hess and Pretori (1894/1970). In this early study, which calls to mind the more modern work by Wallach (1948), observers were presented with two adjacent infield-andsurround patterns, each pattern consisting of a $1.1^{\circ}$ infield square surrounded by a $11.4^{\circ}$ square background region. Each of the four regions was a white surface oriented at a $45^{\circ}$ angle to the observer's line of sight so as to reflect light from a petroleum lamp that moved along a blackened tunnel at right angles to the observer's line of sight (see diagram in Evans, 1948, p. 165). This elegant method allowed good and independent control of, and a valid determination of, the four luminances at a time that predated photometers. The actual slanted position of each of the four regions was not perceived, since each was visible only through a mask containing an aperture that projected a rectangular region to the viewpiont of the observer, with the surround region serving as the mask for the infield.

The infield-surround pattern on the left side was used primarily as a standard, and, for a given series of matches, the luminances of the left-hand infield and the left-hand surround were held constant. Within such a series, the right-hand infield was set at different luminances, and, for each, the observer was required to adjust the righthand surround luminance until the two infields appeared equal in brightness.

Correspondence may be addressed to A. Gilchrist at the Department of Psychology, Rutgers University, Newark, NJ 07102.
In all, the Hess and Pretori study used luminances ranging from 0 to 5,000 units (one unit was equal to 0.12 Hefner-Altenech units, or $0.01 \mathrm{fL}$ ), and tested luminance ratios from less than 1:5,000 to 256:1.

Hess and Pretori's results did not show, as Wallach showed later under somewhat different conditions, that a given luminance ratio on the standard side was matched by the same ratio on the comparison side. What they did show, however, was that any luminance ratio on the standard side could be matched by some comparison ratio, no matter how different the two infields were in luminance. Hess and Pretori (1894/1970) concluded that

the apparent brightness of a small field surrounded by a larger field of different luminance depends on the luminance of the smaller field and on the contrast effect that is present. The apparent brightness of the small field will remain constant if as a result of varying the luminances of the infield and surround field the amount of the variations have a certain relationship independent of their absolute magnitudes. (p. 961)

More recently, the Hess and Pretori results have been invoked by Jameson and Hurvich $(1961,1964)$ as support for their opponent-process theory, according to which the brightness of any surface is the net product of an excitatory effect tied to the luminance of the surface itself and an inhibitory effect associated with the luminance of the surrounding region. According to this view, a surface can appear to lighten, darken, or remain constant as the illumination level increases, depending on a number of factors. Strict lightness constancy is rejected. Jameson and Hurvich (1964) have replotted Hess and Pretori's data in such a way that the horizontal axis represents level 
of illumination, while the vertical axis represents the luminance ratio of the comparison pattern required for a subjective match of the two infields. Had Hess and Pretori obtained strict ratio results (lightness constancy), the data, as plotted by Jameson and Hurvich (1964), would fall into horizontal lines. Instead, the replotting revealed a family of curves varying from almost -1 to a sharply positive function (see Figure 1), similar to the data reported by Jameson and Hurvich (1961) in their own lightness constancy study.

The Hess and Pretori results are particularly relevant to two current controversies in the lightness-brightness field. The first concerns lightness constancy as a fact. Perhaps no one would consider constancy to be completely perfect. On the other hand, if the Hess and Pretori data fairly represent real-world conditions, then their sharply diverging functions represent a state of affairs quite different from our intuitive impression that shades of gray remain remarkably constant across a vast range of natural illumination.

The second controversy involves the relationship between Hess and Pretori's data and those of Wallach (1948). According to Wallach, two infields will appear equally bright only when the infield:surround ratios are the same, and his data show almost no departures from perfect ratio results. Aside from the trivial fact that Wallach used circular infields and surrounds whereas those of Hess and Pretori were square, there seem to be three substantial differences between the two studies. (1) Hess and Pretori's surrounds were adjacent, sharing a common

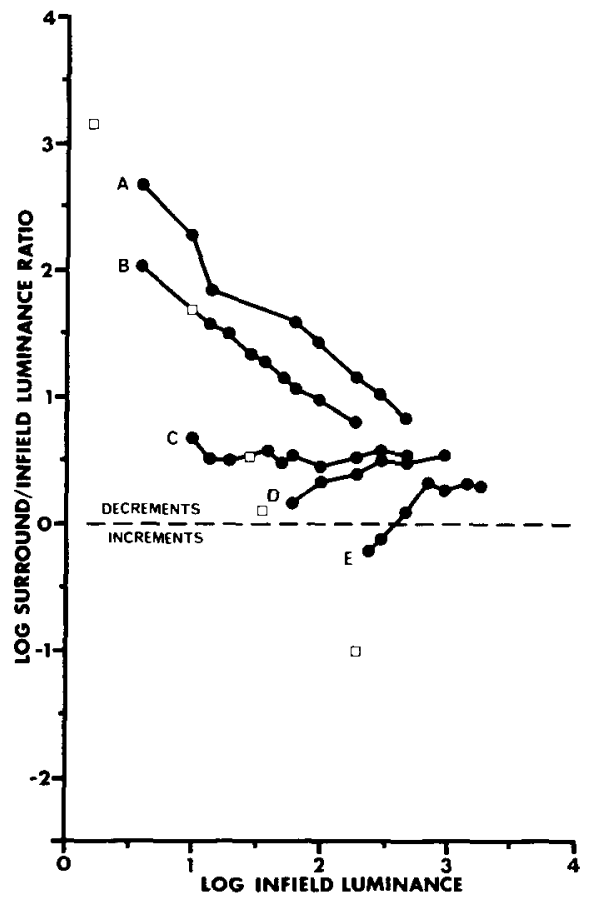

Figure 1. Data from Hess and Pretori (1894/1970). Open squares indicate standard values. Units of measurement, each of which is equal to $0.01 \mathrm{fL}$, are those used by Hess and Pretori. border, whereas Wallach's ring-disk patterns were presented approximately $20^{\circ}$ apart (Wallach, personal communication, October 10, 1981) and were separated by darkness. (2) Hess and Pretori's observers adjusted the surround luminance in response to a preset infield, whereas Wallach's (1948) observers adjusted the infield luminance in response to a preset surround luminance. (3) Hess and Pretori employed a much wider range of luminances than Wallach, both in terms of the range of a single region and the range of the ratio itself.

Wallach's (1976, p. 31) interaction concept suggests the first of these differences as the most likely source of the discrepancy, since the Hess and Pretori paradigm allows the surround on one side to interact neurally with the infield of the other side, complicating the situation.

The second difference (whether the observer adjusts the infield or the surround) should not be important if the ratio principle is valid at all ratio levels. If things are relative, the results should be the same whether the observer manipulates the infield or the surround.

As to the question of the luminance range, we have separately shown (Jacobsen \& Gilchrist, 1988) that the ratio principle holds across a 1-million-to-1 range of illumination and that the earlier report by Jameson and Hurvich (1961), that striking departures from the ratio principle occur when Wallach's (1948) 8-to-1 range of illumination is extended to 12 to 1 , is essentially unreplicable. As for the range of the ratio itself, Wallach never specified whether or not the ratio principle applied beyond the range of ratios possible with reflectance variations alone (100:1 at most), or whether increments (infield brighter than the surround) would behave the same as the decrements he studied. Our previous report (Jacobsen \& Gilchrist, 1988), that brightness constancy (as opposed to lightness constancy) does not exist, suggests that when increments are used in the Wallach (1948) and Hess and Pretori paradigms, observers will match infield luminances, not luminance ratios. Heinemann's (1955) results are consistent with this suggestion, although it should be noted that when the paradigm is changed so as to prevent a comparison of the two surrounds, as in Whittle and Challands's (1969) strict ratio, results are obtained for increments as well.

To untangle these puzzles, we decided to begin by testing Wallach's point concerning the adjacency of the two patterns.

\section{EXPERIMENT 1}

\section{Method}

Observers. Nine naive undergraduate volunteers served as observers, 3 in each of three conditions.

Apparatus. Two pieces of matte opaque white (reflectance $=$ $90 \%)$ paper ( $15 \mathrm{~cm}$ high $\times 10.5 \mathrm{~cm}$ wide) were mounted, each at a $45^{\circ}$ angle to the observer's line of sight but facing away from each other at a $90^{\circ}$ angle. These served as the surround fields. Extending in opposite directions away from these surround fields, and at right angles to the line of sight, were two tunnels, painted black inside, of rectangular cross-section ( $15 \mathrm{~cm}$ high $\times 7.6 \mathrm{~cm}$ wide). 
The right-hand tunnel was $110 \mathrm{~cm}$ long; the left-hand tunnel was $75 \mathrm{~cm}$ long. At the end opposite the surround fields, each tunnel was connected to a larger chamber $(22 \mathrm{~cm}$ high $\times 30 \mathrm{~cm}$ wide $\times$ $30 \mathrm{~cm}$ deep) containing a 500-W floodlight bulb, aimed in the direction of the tunnel. This light chamber was separated from the tunnel by a sliding metal panel that controlled the amount of illumination reaching the surround field. This method of controlling luminance seemed equivalent to the sliding lamp method used by Hess and Pretori, but was simpler to construct.

A black mask ( $23 \mathrm{~cm}$ high $\times 41 \mathrm{~cm}$ wide) containing a rectangular aperture $(7.5 \mathrm{~cm}$ high $\times 15 \mathrm{~cm}$ wide) was mounted immediately in front of the two surround fields. This aperture rendered a rectangular section $\left(11.4^{\circ}\right.$ high $\times 22.8^{\circ}$ wide $)$ visible to the observer. A small trapezoidal aperture was cut into the center of each surround field so that they projected a square image $\left(1.1^{\circ}\right)$ to the viewpoint of the observer. A similar pair of matte white papers was mounted $8 \mathrm{~cm}$ directly behind, but parallel to, the surround fields. These served as the infields, which were visible, of course, only through the central apertures in the surround fields. Each infield panel had its own tunnel parallel to that of its partner surround field, but the two tunnels shared a common light chamber at the end. The apparatus was constructed in two separate sections, so that the left and right fields could be separated as much as desired.

The observer sat facing the apparatus, placing his or her head against a headrest that consisted of a rectangular board, $40 \mathrm{~cm}$ wide $\times 30 \mathrm{~cm}$ high, that contained two viewing tubes, $7.5 \mathrm{~cm}$ long and $4.5 \mathrm{~cm}$ in diameter, mounted $4 \mathrm{~cm}$ apart $(10 \mathrm{~cm}$ center-to-center $)$. Except for the haploscopic condition, all viewing was monocular, through an aperture $4 \mathrm{~mm}$ in diameter (to control pupil size) in a cover of the right-hand tube. In the haploscopic condition, a mirror was mounted directly behind the left-hand tube (fitted with the same 4-mm aperture), at a diagonal to the line of sight. The observer's eyes were thus located $50 \mathrm{~cm}$ in front of the mask that de fined the borders of the surround fields.

Design. Matches were made under three conditions:

1. Surrounds contiguous. This condition was a strict replication of Hess and Pretori's display, with the surround fields adjacent along a common border. Viewing was monocular, using the right eye, and free, except for the headrest.

2. Surrounds apart. The left-hand surround field was moved to a position $90^{\circ}$ to the observer's left, while the right-hand field remained straight ahead of the observer. A second headrest, mounted at right angles to the first, was used for viewing the left-hand field. Viewing for each field was monocular and free, but head movements were required.

3. Haploscopic. The right-hand field remained straight ahead of the observer and was seen by the observer's right eye. The lefthand field was presented to the observer's left eye by means of the diagonally mounted mirror. In the binocular view, the two fields were separated by $65^{\circ}$ of darkness.

Procedure. Observers were brought into the lab and seated in front of the apparatus, which was dark. The fields were then turned on and the observer was shown how to adjust the luminance of the right-hand surround by turning a knob. The observer was then instructed to adjust the right-hand surround until the two infields appeared equal in lightness and/or brightness. There were 50 trials altogether for a single observer, 2 for each of the five infield settings within each of the five series. Trials alternated between ascending (right-hand surround initially dark) and descending.

Instructions. The following was read to each observer as he or she was seated in front of the viewing apparatus:

In this experiment, you will be asked to look into this viewing apparatus. On your left you will see a small square target in the middle of a large rectangle. I will be setting this target on your left to various brightnesses and shades of gray. On your right [or "straight ahead of you" in the case of surrounds apart] you will see a similar target and surround display. Your task will be to match the shade of gray of these two small targets, if possible. In some cases where the target appears luminous please match the two small targets in terms of brightness. You will accomplish this by using this knob that controls the brightness of the surround on your right. You will notice that this changes the appearance of the small target on your right. Remember, adjust this knob until the two small targets appear the same shade of gray, or until the two targets appear equal in brightness when the targets appear luminous. Any questions?

\section{Results}

The resulting data are shown graphically in Figures 2, 3 , and 4. In general we obtained the same pattern of results that Hess and Pretori had obtained. The separation of the fields produced somewhat flatter functions in Conditions 2 and 3 than in Condition 1 for Series C (slopes of .06 and .07 as opposed to .19) and for Series D (slopes of .02 and .03 as opposed to .17), but made little difference for the other series.

\section{Discussion}

Despite the fact that we had obtained almost the same results as Hess and Pretori, at least two reasons for skepticism remained. Hess and Pretori's curves (as well as our own) seemed to cut blithely across some qualitative boundaries that other work had suggested ought to have distinct effects on the data. One of these is the boundary between increments and decrements. Usually, when given a choice, observers will not match an increment to a decrement (Burgh \& Grindley, 1962; Heinemann, 1955; Whittle, 1986; Whittle \& Challands, 1969), and when forced to do so, observers find the match difficult and they are usually not satisfied with it. Second, our previous results

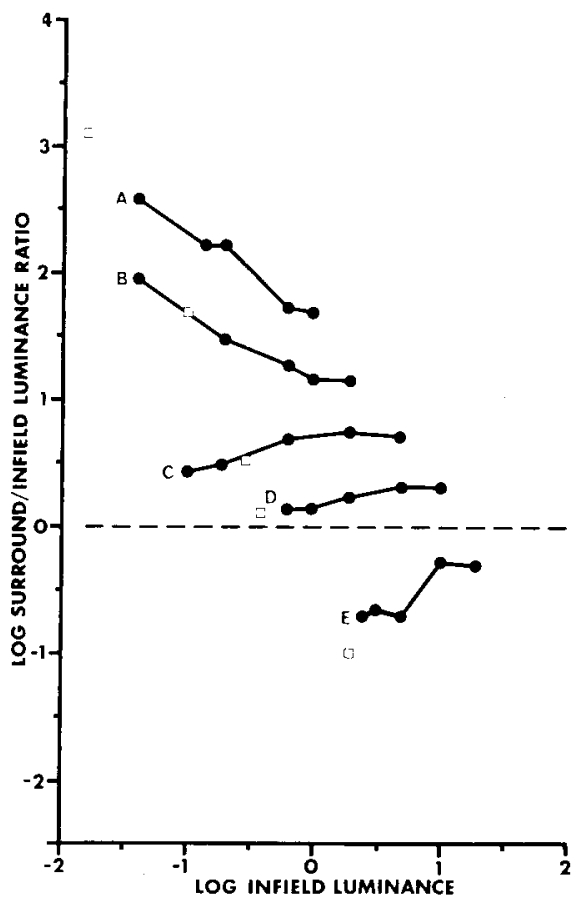

Figure 2. Data from Experiment 1 (in footlamberts), Condition 1 (surrounds contiguous). 
(Jacobsen \& Gilchrist, 1988), consistent with those of Heinemann, suggest that, in the Hess and Pretori paradigm, only decrements will lead to ratio matching. Increments ought to produce luminance matching, which would show up in the Jameson and Hurvich replot as a vertical line. No vertical lines appeared at all, but the reason is very simple: such matches were excluded under the Hess and Pretori procedure! Hess and Pretori's observers were not given control over the infield luminance, so they could not have matched for luminance. The luminance of the comparison infield was systematically varied by the experimenter, forcing the data into some slope other than a vertical line.

Besides the increment-decrement distinction, a second qualitative distinction emerged as we studied our display in an attempt to understand the results. One of us (A.J.) noticed that, when the infield was a decrement, increases in the surround luminance produced a decrease in the brightness of the infield only up to a point. When the surround luminance acquired approximately 100 times the luminance of the infield, the infield appeared as dark as possible - totally dark. Further increases in the surround luminance had no effect on infield brightness. Yet no such "darkness threshold"' (Whittle [1986] calls it the "black limit") shows up in the Hess and Pretori data. Instead, the region beyond this hypothetical threshold, which we have dubbed the "zone of equivalence," contains quite a number of curves representing very systematic data. If all decrements beyond some threshold appear indistinguishable, all totally and equally dark, then the Hess and Pretori curves could not possibly represent matches of the

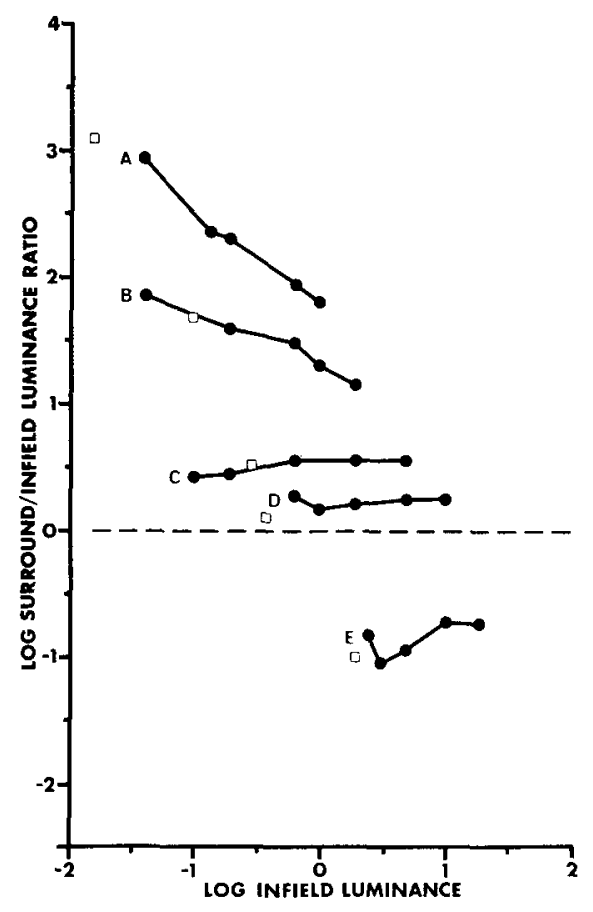

Figure 3. Data from Experiment 1 (in footlamberts), Condition 2 (surrounds apart).

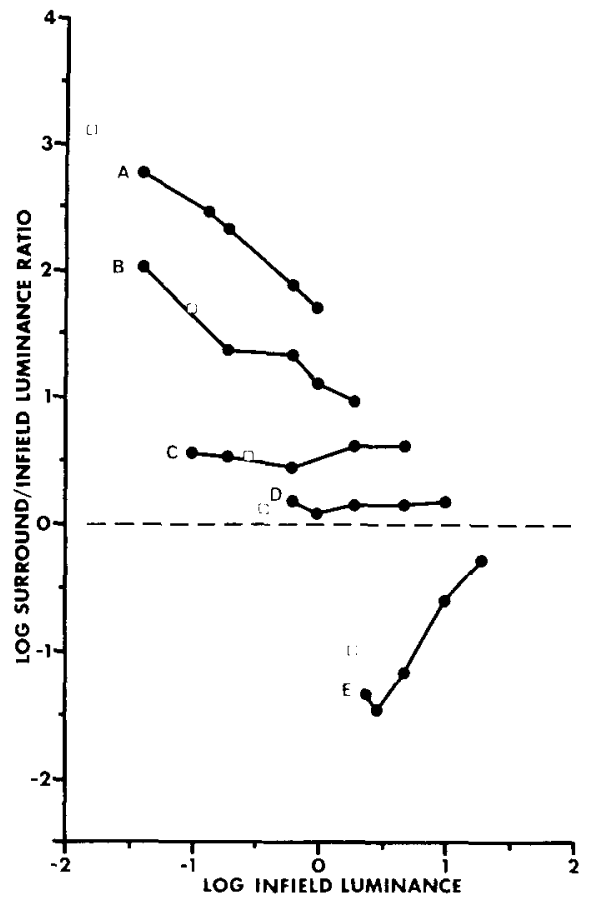

Figure 4. Data from Experiment 1 (in footlamberts), Condition 3 (haploscopic).

two infields, which could at best produce random results. But what could these curves represent?

Before speculating too much, we decided to test this idea of a zone of equivalence in two ways: (1) by conducting a forced-choice discrimination study (Experiment 2) using a surround:infield ratio well above the darkness threshold, and (2) by a direct measure of our hypothesized darkness threshold, that is, the boundary at which further increases in surround luminance exert no further darkening effect on the infield (Experiment 3).

\section{EXPERIMENT 2}

\section{Method}

Six additional observers served, 3 in each run.

Two runs were conducted. In the first, both surrounds, left and right, were set at $35.7 \mathrm{fL}$. The standard infield was set at $.062 \mathrm{fL}$, producing a surround:infield ratio of 576:1. The comparison infield was set at either .02 or $.12 \mathrm{fL}$, producing ratios of either $1,785: 1$ or $298: 1$. The two comparison infield values were varied randomly, and on each trial the observer was simply required to tell which infield was brighter.

In the second run, the surrounds were again set at $35.7 \mathrm{fL}$, the standard infield at $.17 \mathrm{fL}$, and the comparison infield at either .02 or $.265 \mathrm{fL}$. Thus, the standard ratio of $210: 1$ was compared with comparison ratios of either $1,785: 1$ or $135: 1$.

Each observer made 16 choices, making 48 total choices in each run. All viewing was haploscopic, as in Condition 3 of $\mathrm{Ex}$ periment 1 .

\section{Results}

In the first run, out of 192 responses, 88 were correct and 104 were incorrect. In the second run, 100 responses 
were correct and 92 were incorrect. A chi-square test was done on each individual observer's performance. The results of these tests were: $\chi^{2}(1)=.06(p<.90), 1.00$ $(p<.20), \quad 1.56 \quad(p<.20), \quad 0 \quad(p<.995), 2.25$ $(p<.10)$, and $.25(p<.0)$, respectively, for Observers 1 through 6 . Hence, the null hypothesis (that the targets are indistinguishable) could not be rejected for any one observer.

\section{EXPERIMENT 3}

\section{Method}

Four additional observers served.

Standard and comparison surround luminances were always equal. Four surround luminance values were used (in random order): 52.3, $7.5,1.03$, and $.144 \mathrm{fL}$. The comparison infield was always set so as to produce a standard surround:infield ratio of 1,000:1. At each surround luminance level, the comparison infield luminance was initially set equal to its surround and the observer was asked to reduce the infield luminance until it just began to appear equal to the standard infield. On alternate trials, the infield was set at zero and the observer increased its luminance until it just began to appear different from the standard infield. They were allowed to repeat these maneuvers as many times as necessary to establish their confidence in the measure. Each observer made two ascending and two descending trials (in random order) at each surround luminance.

\section{Results}

The results are shown graphically in Figure 6, along with the results of Experiment 5. The average slope for the best-fitting straight line for these data is .27 .

\section{Discussion}

The fact that we could measure a threshold ratio beyond which all infields appeared identical, regardless of surround:infield ratio, seems to establish the fact that at least Series A of Hess and Pretori's curves could not represent what they are assumed to represent, namely infield matching. We now believe that they actually represent surround matching. Even though this would be in direct violation of the observer's instructions, surround matching is not as unreasonable as it may at first seem. First, within the zone of equivalence, the infields will appear equal from the beginning of the trial and will remain so, possibly causing the observer to wonder what the experimenter is actually seeking. Second, surround luminance happens to be the only value over which the observer has direct control. Third, for these dark infields, a bright surround casts a faint sort of haze or fog over the infield, possibly related to the veiling luminance produced by glare (Gilchrist \& Jacobsen, 1983; Hering, 1874/1964; Rushton \& Gubisch, 1966). It may be this that the observer is attempting to match. At any rate, if the infields appear equal to begin with, it would not be unreasonable for the observer to attempt to place them in equal contexts, in an attempt to make the infields even more equal.

Surround matching would show up in the Jameson and Hurvich (1964) graph as a slope of -1 , and this is approximated by the curves in question. Yet the departures from -1 slope (which are systematic, not random), however slight, are nonetheless puzzling, since matching the luminance of the surrounds should be very precise inasmuch as they share a common boundary. We suspected that the departures from a -1 slope might be associated with the fact that, under the Hess and Pretori procedure, observers are free to reduce the comparison luminance to zero. This maneuver would transform the comparison infield to a luminous-appearing increment, much brighter in appearance than the standard infield, which continues to appear as dark as possible. This may explain why observers invariably set the comparison surround to a value at least slightly higher than the standard surround. Perhaps the experience of seeing the comparison infield so much brighter than the standard infield biased the observers to set the comparison surround at least somewhat brighter than the standard surround. To test this possibility, we conducted a very brief experiment in which a limit was placed on the apparatus so that the observer could not reduce the luminance of the comparison surround below a value 200 times that of the comparison infield. This constraint not only prevented the comparison infield from ever appearing as an increment, but also prevented it from appearing as any shade of surface gray.

\section{EXPERIMENT 4}

\section{Method}

Data were obtained from 3 additional observers for Series A (tope curves, Figures 1-4). The standard surround was set at $20.5 \mathrm{fL}$, the standard infield at $0.0151 \mathrm{fL}$, and the apparatus was modified

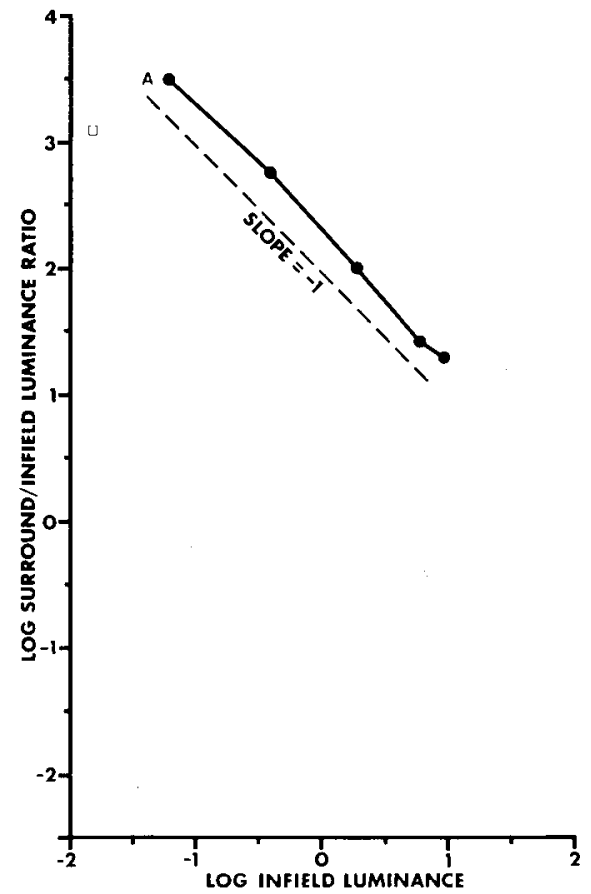

Figure 5. Data from Experiment 4 (in footlamberts). 
so that the comparison surround could never be set lower than 200 times the comparison infield luminance. Viewing was haploscopic, and the procedure was the same as in Experiment 1.

\section{Results}

The data obtained produced a curve with a slope of -1.03. This can be seen in Figure 5.

\section{Discussion}

These results appear to explain how Hess and Pretori obtained systematic data in the zone of equivalence, where all infields should be indistinguishable.

The next sil seemed clear. The whole of Experiment 1 should be repeated with observers controlling the comparison infield rather than the comparison surround. This would prevent surround-matching. Infield control would also be a fairer procedure for the zone of increments, since observers would thereby be free to match either infield luminance or luminance ratios (infield:surround).

Our predictions were quite distinct and corresponded to the three qualitative zones of the graph. For the zone of equivalence, we predicted chaotic results with high variability, since all infields should be indistinguishable and surround matching was prevented. For the remainder of the region of decrements (between the dark threshold and the increment/decrement threshold), which could be called the surface lightness zone, we predicted parallel, horizontal curves--that is, lightness constancy. For the zone of increments, we predicted vertical curves - that is, luminance matching, or zero constancy.

\section{EXPERIMENT 5}

\section{Method}

Eight additional naive observers served, 4 in each of the two runs. The method was the same as in Experiment 1 except for the use of infield control and the fact that the haploscopic method was used exclusively. This experiment was run twice, once using an arbitrary set of comparison surround values (Run 1) and once using the same comparison surround values that Hess and Pretori obtained from their observers (Run 2).

\section{Results}

The data are presented in Tables 1 and 2, and the results for the second run are shown graphically in Figure 6. The only series clearly located in the zone of equivalence was Series A, and, as expected, the data do not fall into any simple pattern. More importantly, the range of matches for Series A was extremely wide, as can be seen in the standard deviations indicated on the graph. Compare these deviations with the much tighter deviations for the other curves.

The lines of best fit for Series B, C, and D, the three series within the surface lightness zone, produced slopes of $.52, .09$, and .03 , respectively, for the first run and slopes of $.24, .09$, and .01 , respectively, for the second run.

Table 1

Log Luminances of Standard and Comparison Fields for Experiment 5, First Run

\begin{tabular}{|c|c|c|c|c|c|c|c|c|}
\hline \multirow[b]{2}{*}{ Series } & \multicolumn{2}{|c|}{ Infield } & \multicolumn{2}{|c|}{ Surround } & \multicolumn{2}{|c|}{ S:I Ratio } & \multirow{2}{*}{$\begin{array}{c}\text { Infield } \\
S D\end{array}$} & \multirow[b]{2}{*}{ Slope } \\
\hline & Std. & Comp. & Std. & Comp. & Std. & Comp. & & \\
\hline A & -1.55 & $\begin{array}{l}-1.24 \\
-1.54 \\
-1.14 \\
-1.90 \\
-2.75\end{array}$ & 1.58 & $\begin{array}{r}2.01 \\
1.49 \\
.87 \\
.38 \\
-.44\end{array}$ & 3.13 & $\begin{array}{l}3.25 \\
3.03 \\
2.01 \\
2.28 \\
2.31\end{array}$ & $\begin{array}{l}.71 \\
.59 \\
.23 \\
.48 \\
.04\end{array}$ & .24 \\
\hline B & -.17 & $\begin{aligned} & .003 \\
&-.11 \\
&-.44 \\
&-.75 \\
&-1.52\end{aligned}$ & 1.54 & $\begin{array}{r}1.99 \\
1.49 \\
.87 \\
.38 \\
-.44\end{array}$ & 1.71 & $\begin{array}{l}1.99 \\
1.60 \\
1.31 \\
1.13 \\
1.08\end{array}$ & $\begin{array}{l}.08 \\
.08 \\
.06 \\
.05 \\
.10\end{array}$ & .52 \\
\hline $\mathrm{C}$ & .41 & $\begin{array}{r}1.34 \\
.95 \\
.21 \\
-.53 \\
-1.21\end{array}$ & .94 & $\begin{array}{r}1.99 \\
1.49 \\
.60 \\
-.30 \\
-.82\end{array}$ & .53 & $\begin{array}{l}.65 \\
.54 \\
.39 \\
.23 \\
.39\end{array}$ & $\begin{array}{l}.10 \\
.05 \\
.02 \\
.02 \\
.04\end{array}$ & $\begin{array}{r}.12 \\
.12\end{array}$ \\
\hline D & .75 & $\begin{array}{r}1.52 \\
1.33 \\
.55 \\
-.23 \\
-1.02\end{array}$ & .98 & $\begin{array}{r}1.62 \\
1.41 \\
.57 \\
-.21 \\
-1.00\end{array}$ & .23 & $\begin{array}{l}.10 \\
.08 \\
.02 \\
.02 \\
.02\end{array}$ & $\begin{array}{l}.01 \\
.01 \\
.02 \\
.02 \\
.03\end{array}$ & .03 \\
\hline $\mathbf{E}$ & 1.85 & $\begin{array}{l}1.36 \\
1.37 \\
1.37 \\
1.34 \\
1.35\end{array}$ & .94 & $\begin{array}{r}.24 \\
-.20 \\
-.56 \\
-1.07 \\
-1.70\end{array}$ & -.91 & $\begin{array}{l}-1.12 \\
-1.57 \\
-1.93 \\
-2.41 \\
-3.05\end{array}$ & $\begin{array}{l}.13 \\
.08 \\
.16 \\
.08 \\
.03\end{array}$ & 34.62 \\
\hline
\end{tabular}

Note-Std. = standard; Comp. = comparison; $\mathbf{S : I}=$ surround infield ratio. 
Table 2

Log Luminances of Standard and Comparison Fields for Experiment 5, Second Run

\begin{tabular}{|c|c|c|c|c|c|c|c|c|}
\hline \multirow[b]{2}{*}{ Series } & \multicolumn{2}{|c|}{ Infield } & \multicolumn{2}{|c|}{ Surround } & \multicolumn{2}{|c|}{ S:I Ratio } & \multirow{2}{*}{$\begin{array}{c}\text { Infield } \\
S D\end{array}$} & \multirow[b]{2}{*}{ Slope } \\
\hline & Std. & Comp. & Std. & Comp. & Std. & Comp. & & \\
\hline A & -1.82 & $\begin{array}{l}-1.93 \\
-1.94 \\
-2.12 \\
-2.48 \\
-2.70\end{array}$ & 1.31 & $\begin{array}{r}1.74 \\
.56 \\
.09 \\
-.39 \\
-.94\end{array}$ & 3.13 & $\begin{array}{l}3.68 \\
2.50 \\
2.21 \\
2.09 \\
1.75\end{array}$ & $\begin{array}{l}.30 \\
.89 \\
.39 \\
.18 \\
.03\end{array}$ & .68 \\
\hline B & -1.00 & $\begin{array}{r}-.46 \\
-.77 \\
-1.46 \\
-1.89 \\
-2.70\end{array}$ & .71 & $\begin{array}{r}1.74 \\
1.14 \\
.09 \\
-.39 \\
-1.02\end{array}$ & 1.71 & $\begin{array}{l}2.21 \\
1.91 \\
1.55 \\
1.50 \\
1.68\end{array}$ & $\begin{array}{l}.07 \\
.17 \\
.07 \\
.08 \\
.03\end{array}$ & .24 \\
\hline $\mathrm{C}$ & -.55 & $\begin{aligned} & .33 \\
& .015 \\
&-1.005 \\
&-1.91 \\
&-2.35\end{aligned}$ & 0.0 & $\begin{array}{r}1.06 \\
.66 \\
-.44 \\
-1.34 \\
-1.94\end{array}$ & .55 & $\begin{array}{l}.74 \\
.64 \\
.57 \\
.57 \\
.41\end{array}$ & $\begin{array}{l}.05 \\
.08 \\
.02 \\
.01 \\
.08\end{array}$ & .09 \\
\hline D & -.43 & $\begin{array}{r}.925 \\
-.19 \\
-.76 \\
-1.52 \\
-1.97\end{array}$ & -.31 & $\begin{array}{r}1.06 \\
.33 \\
-.70 \\
-1.36 \\
-1.80\end{array}$ & .12 & $\begin{array}{l}.14 \\
.14 \\
.06 \\
.16 \\
.17\end{array}$ & $\begin{array}{l}.01 \\
.03 \\
.03 \\
.04 \\
.03\end{array}$ & .01 \\
\hline $\mathrm{E}$ & .3 & $\begin{array}{l}.32 \\
.28 \\
.28 \\
.28 \\
.23\end{array}$ & -.7 & $\begin{array}{c}0.0 \\
-.82 \\
-1.10 \\
-1.70 \\
-2.10\end{array}$ & -1.0 & $\begin{array}{l}-.32 \\
-1.11 \\
-1.38 \\
-1.98 \\
-2.33\end{array}$ & $\begin{array}{l}.04 \\
.06 \\
.05 \\
06 \\
.05\end{array}$ & 21.93 \\
\hline
\end{tabular}

Note-Std. = standard; Comp. $=$ comparison; $\mathrm{S}: \mathrm{I}=$ surround infield ratio.

Series E, located in the zone of increments, produced a curve that is extremely close to a vertical line, with a slope of 34.62 for the first run and 21.93 for the second.

\section{Discussion}

In general, the results are consistent with our predictions for the three zones. Within the zone of equivalence, the data are quite chaotic, a fact that is obscured somewhat by our presentation of a curve made up of means (Figure 6). Such means are not very meaningful when observer matches vary so much. The standard deviations illustrate this variability.

Within the zone of increments, we obtained almost perfect luminance matching (means of $.32, .28, .28, .28$, and .23 to match the standard infield of .30). This is consistent with Wallach's (1976) observation that when the infield has the higher intensity "it will look white and a change in the ratio will not affect the color as such" (p. 10), and with what both we (Jacobsen \& Gilchrist, 1988) and Heinemann (1955) have found for increments in similar paradigms. These converging findings have yet to receive a good theoretical explanation. It seems that Wallach's concept of separation of systems (each infield seen only in relation to its immediate context) applies only to decrements. In this kind of side-by-side comparison, at least, it seems to be possible to relate both infields to each other within some common frame of reference,

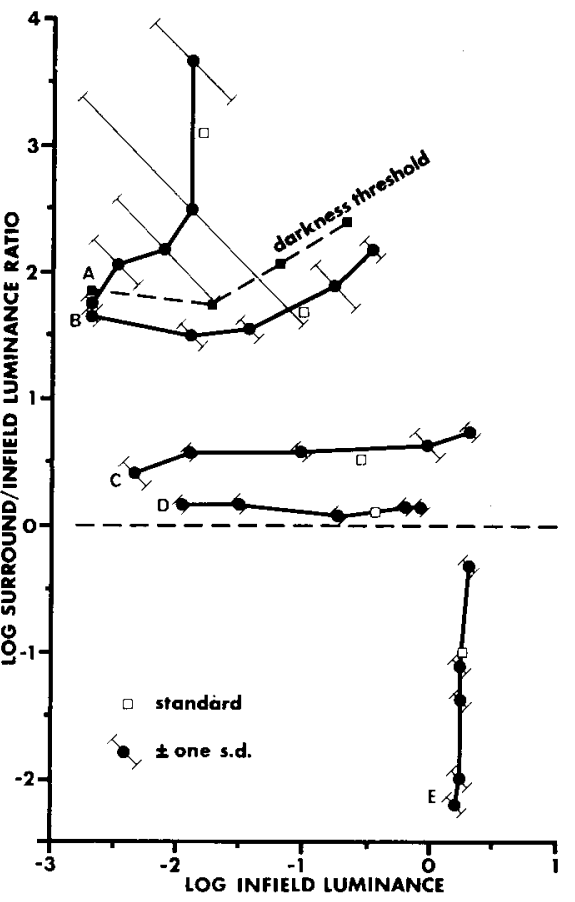

Figure 6. Data from Experiment 3 (darkness threshold) and Experiment 5 , Run 2 (in footlamberts). 
perhaps by means of the edge integration concept described by Arend (1973), Gilchrist (1979), Gilchrist, Delman, and Jacobsen (1983), and Land and McCann (1971). When Whittle and Challands (1969) prevented this kind of edge integration by binocularly superimposing the surrounds, virtually perfect ratio-matching was obtained, even for increments.

Within the zone of surface lightness, the curves are closer to horizontal lines than in either the Hess and Pretori study or any of the three conditions of our Experiment 1. However, these curves tend to slope upward at their right-hand ends for some reason that has eluded us so far. This applies as well to the darkness threshold curve. This puzzling result should be dealt with in the near future, since there are compelling reasons, both theoretical and empirical (Heinemann, 1955; Jacobsen \& Gilchrist, 1988; Wallach, 1948; Whittle \& Challands, 1969), to expect flat functions.

Especially in combination with our other findings (Jacobsen \& Gilchrist, 1988) that the ratio principle holds over a 1-million-to-1 range of illumination, these results seriously undermine the Jameson and Hurvich (1961) claim of diverging functions. Despite the fact that we did not obtain the same degree of flatness in this study as we did in the 1-million-to-1 study, we suggest that it would not be prudent to cite our departures from flatness (in Series $\mathbf{B}$ and the dark-threshold curve) as residual evidence for the "intensity dependence" of lightness perception. For one thing, these departures from constancy are precisely opposite in direction (positive rather than negative) to those of the original Hess and Pretori study.

Our findings indicate that there are limitations on the Wallach ratio principle, but that the limitations do not concern the levels of absolute luminance. They concern qualitative relationships among luminance ratios. The ratio principle does not apply to increments (at least not in this type of display); nor does it apply to decrements in which the surround:infield ratio is greater than about 100:1. Between these two zones, however, within the surface lightness zone, the conclusion most strongly supported is that lightness is a relative affair, depending essentially on surround:infield luminance ratio, regardless of absolute levels.

\section{REFERENCES}

AREND, L. E. (1973). Spatial differential and integral operations in human vision: Implications of stabilized retinal image fading. Psychological Review, 8, 374-395.

Burgh, P., \& Grindley, G. C. (1962). Size of test patch and simultaneous contrast. Quarterly Journal of Experimental Psychology, 14, 89-93.

Evans, R. M. (1948). An introduction to color. New York: Wiley.

GILCHRIST, A. (1979). The perception of surface whites and blacks. Scientific American, 24, 88-97.

Gilchrist, A., Delman, S., Jaconsen, A. (1983). The classification and integration of edges as critical to the perception of reflectance and illumination. Perception \& Psychophysics, 33, 425-436.

GilCHRIST, A. L., \& JACOBSEN, A. (1983). Lightness constancy through a veiling luminance. Joumal of Experimental Psychology, 9, 936-944.

HeinemanN, E. G. (1955). Simultaneous brightness induction as a function of inducing and test-field luminances. Joumal of Experimental Psychology, 50, 89-96.

HeRING, E. (1964). Outlines of a theory of the light sense (L. M. Hurvich \& D. Jameson, Trans.). Cambridge, MA: Harvard University Press. (Original work published 1874)

Hess, C., \& Pretori, H. (1970). Quantitative investigation of the lawfulness of simultaneous brightness contrast (H. R. Flock \& J. H. Tenney, Trans.). Perceptual \& Motor Skills, 31, 947-969. (Original work published 1894)

JACOBSEN, A., \& Gilchrist, A. L. (1988). The ratio principle holds over a million-to-one range of illumination. Perception \& Psychophysics, 43, 1-6.

JAMESON, D., \& HuRvich, L. M. (1961). The complexities of perceived brightness. Science, 133, 174-179.

JAMESON, D., \& HuRviCh, L. M. (1964). Theory of brightness and color contrast in human vision. Vision Research, 4, 135-154.

LAND, E. H., \& MCCANN, J. J. (1971). Lightness and retinex theory. Joumal of the Optical Society of America, 61, 1-11.

Rushton, W. A. H., \& Gubisch, R. W. (1966). Glare: Its measurement by cone thresholds and by bleaching of cone pigments. Journal of the Optical Society of America, 56, 104-110.

WALLACH, H. (1948). Brightness constancy and the nature of achromatic colors. Journal of Experimental Psychology, 38, 310-324.

Wallach, H. (1976). On perception. New York: NYT, Quadrangle.

WhitTLE, P. (1986). Increments and decrements: Luminance discrimination. Vision Research, 26, 1677-1691.

Whittle, P., \& Challands, P. D. C. (1969). The effect of background luminance on the brightness of flashes. Vision Research, 9, 1095-1110.

(Manuscript received April 22, 1987; revision accepted for publication July 17, 1987.) 